\title{
EXPERIMENTAL INVESTIGATION OF THE EFFECT OF THE AIR INLET ANGLE AND THE COMBUSTION PRESSURE IN A DUCTED ROCKET COMBUSTOR
}

\author{
V. Laguzzi ${ }^{1}$, F. Molinaro ${ }^{1}$, and B. $\operatorname{Natan}^{2}$ \\ ${ }^{1}$ Department of Aerospace Engineering, Politecnico di Milano \\ Milan 20156, Italy \\ ${ }^{2}$ Faculty of Aerospace Engineering \\ Technion - Israel Institute of Technology \\ Technion City, Haifa 32000, Israel
}

\begin{abstract}
The scope of the study is to evaluate the combustion efficiency of a ducted rocket combustor operating at different conditions, using a connected-pipe testing setup. An experimental parametric investigation was conducted to evaluate the effect of the inlet air-injection angles and the effect of the combustion pressure for different fuel-to-air ratios. The experimental results indicate that best energetic performance was obtained for an injection angle of $120^{\circ}$, i. e., against the main flow direction. The reason is that this way better mixing was obtained and the residence time increased. Characteristic velocity was found to decrease with decreasing the combustion pressure.
\end{abstract}

\section{NOMENCLATURE}

$c^{*}$ characteristic velocity

$C_{D}$ discharge coefficient

$D_{c}$ diameter of the secondary combustor

$D_{e}$ exhaust nozzle exit diameter

$D_{f}$ diameter of the fuel inlet

$D_{i}$ diameter of the air inlet

$D_{t}$ exhaust nozzle throat diameter

$f_{c}$ fuel-to-air mass ratio in the secondary combustor

$f_{g}$ fuel-to-air mass ratio in gas generator

$I_{\mathrm{sp}}$ specific impulse

$L_{c}$ length of the combustor

(C) The Authors, published by EDP Sciences. This is an open access article distributed under the terms of the Creative Commons Attribution License 4.0 (http://creativecommons.org/licenses/by/4.0/). 
$L_{d}$ length of the dome region

$L_{i}$ length of the air inlet region

$\dot{m}_{a}$ mass flow rate of the vitiated air

$\dot{m}_{f}$ mass flow rate of the fuel-rich gas

$P_{c}$ combustion chamber pressure

$T_{c}$ combustion chamber temperature

$\eta_{c^{*}}$ efficiency of characteristic velocity

$\theta \quad$ inclined angle of the air injector

$\varphi$ equivalence ratio

\section{Subscript}

exp experimental

th theoretical

\section{INTRODUCTION}

Ducted rockets (ram-rockets) combine the advantages of solid rockets with the long flight capability of air-breathing engines. They have significant advantages in comparison to rocket engines such as high specific impulse, long flight range, high terminal velocity, and throttleability [1]. In a typical operation, a ducted rocket is accelerated by an integrated solid rocket booster to supersonic velocity after launching. The dual mode combustion chamber, which contains the solid propellant for the booster operation, serves as the secondary combustor for the sustainer operation, when the propellant is completely burned. The ram air, compressed by several shockwaves at the intakes and decelerated in the diffuser, is supplied into the secondary combustor through the multiple side inlets. The fuel-rich gas, produced from the gas generator (primary combustion chamber), is injected from the head end of the secondary combustor. Then, it mixes and reacts with the incoming hot air in the secondary combustor.

The turbulent flow in the ducted combustor is quite complicated since it includes the recirculation stream, jet impingement between air to air and air to fuel, separation and reattachment, etc. Moreover, many research groups [2-6] focused on the variable flow ducted rocket (VFDR), which is able to achieve sufficient flight capability in full airspace and fulfill the various mission requirements for the high mobility. On the other hand, the variable flow approach carries a complexity of the flow environment in the combustor. Its thrust is controlled to accomplish the dynamic flight mission such as flight velocity, altitude, and attitude of a missile; throttling can be actively performed by regulating the fuel flow through control of the nozzle throat size of the gas generator. Simultaneously, stagnation properties and flow rate of the incoming air through the side 
inlets are determined by the varied flight conditions depending on the throttling of the gas generator. These changes of the operating conditions, which can occur during flight, necessarily result in changes of the thermochemical and aerodynamic parameters such as equivalence ratio and momentum ratio (MR) between air and fuel.

The geometric parameters including the number of air inlets, air inlet angle, dome height, fuel entrance location and the number of fuel inlets, etc. have a direct effect on the air/fuel mixing, flow structure, and combustion phenomena [7]. In particular, the air inlet shape [8], i.e., configuration, location, and arrangement of the side air inlet and dome height, can be regarded as a dominant design factor which determines the performance. For example, thrust depends on the captured air mass flow and the total pressure recovery, stability from buzz and backflow, maneuver capabilities, and drag reduction [9]. Flow visualization and combustion experiments [10-14], which consider the effect of the various flow conditions and geometric parameters of the combustor involving air inlets, have been conducted in various studies. Although some data on the air inlet geometry effects in a limited range of operating condition have been obtained in previous studies, additional information under various air inlet geometries and operating conditions is required for comparison and verification.

Kim and Natan [14] conducted connected-pipe combustion experiments and a numerical analysis of the internal reacting flow in a ducted rocket combustor at various equivalence ratios with an emphasis on the air inlet geometry effect. They used three kinds of combustors in order to evaluate the air inlet geometry effect; a two-inlet combustor with inlet angle of $90^{\circ}$, a two-inlet combustor with inlet angle of $180^{\circ}$, and a four-inlet combustor with inlet angle of $90^{\circ}$. The four-inlet combustor exhibited the best combustion efficiency and the two-inlet combustors did not show large differences in terms of performance.

The scope of the present study is to evaluate the energetic performance of a ducted rocket combustor operating at different conditions, using a connectedpipe testing setup at the Rocket Propulsion Center at the Faculty of Aerospace Engineering of the Technion-IIT. The experimental setup is based on the work of Kim and Natan [14].

An experimental parametric investigation was conducted to evaluate the effect of the inlet air-injection angles and the effect of the combustion pressure for different fuel-to-air ratios.

The various operating conditions, in terms of altitude and speed, are simulated by changing the fuel-to-air ratio and the pressure in the combustion chamber; any change in altitude or in speed results in a variation of the mass flow rate of air entering the intakes, i. e., of the fuel-to-air ratio and the combustion chamber pressure.

To simulate the combustion products of a gas generator, a fuel-rich mixture of ethylene and air was used to simulate a solid fuel of glycidyl azide polymer (GAP) including 5\%(wt.) carbon. The chosen configuration consisted of four 
inlets, $90^{\circ}$ apart. Three injection angles were examined, $60^{\circ}, 90^{\circ}$, and $120^{\circ}$, and various pressures in the range $2.5-6.5$ bar.

\section{EXPERIMENTAL INVESTIGATION}

\subsection{Simulant Fuel Mixture for the Gas Generator}

A typical solid fuel for the gas generator of ducted rockets is essentially a fuelrich solid propellant with minimum proportion of oxidizer for the self-sustaining combustion capability. Also, fuel-rich propellants with high burning rates and high pressure exponents are required to achieve a wide range of fuel flow in a VFDR [15]. In this respect, GAP is a fairly attractive candidate for ducted rockets. Despite the low concentration of oxygen atoms, GAP is a highly energetic material with self-sustaining burning characteristics. Furthermore, it can be decomposed rapidly under the low combustion temperature and fuel-rich decomposition products are produced during combustion [16]. The GAP-based propellants have demonstrated a significant capability as effective fuels for the gas generator in several research groups $[5,12,16]$. Thus, such a propellant was chosen for the gas generator in the present study.

Simulant fuel mixtures that consist of gaseous or liquid phase ingredients have been widely employed for research and development of gas generators. This approach can save the time and cost related to the manufacturing and handling of a solid fuel for each evaluation test. Also, it can offer sufficient accuracy and eliminate a difficulty in terms of burning rate control of the actual solid fuel. Because of these benefits, for the gas generator of the present study, a fuel-rich mixture $\left(f_{g}=0.77\right)$ of ethylene and air was used to simulate a solid fuel of GAP including $5 \%$ (wt.) carbon. The validity of this approach is further proved by the overall products of the GAP/carbon and ethylene/air.

Table 1 presents the properties and species concentrations of two cases at baseline operating condition of the gas generator, calculated using the Gordon and McBride chemical equilibrium code (CEA) [17] at gas generator operating pressure of 1.35 $\mathrm{MPa}$. Good agreement is obtained for the calculated equilibrium exhaust properties of two kinds of mixtures. Considering that the measurement of the exhaust gas properties and collection of exhaust compositions is difficult, as shown in Table 1, the existence of a significant amount of carbon product can be a good evidence of thermochemical equilibrium condition. Moreover, this assumption is further supported by the fact that the pressure and temperature values within the gas generator, measured experimentally, are very close to the calculated equilibrium values.

This large carbon fraction shows that the fuel-rich exhaust products need to be separated into gaseous products and solid carbon for the better accuracy of 
Table 1 Comparison of the exhaust products of a fuel-rich solid propellant and a simulant fuel mixture ${ }^{a}$

\begin{tabular}{ccc}
\hline & GAP/carbon & Ethylene/air \\
\hline Temperature, $\mathrm{K}$ & 1261 & 1164 \\
Density, $\mathrm{kg} / \mathrm{m}^{3}$ & 1.56 & 1.55 \\
\hline \multicolumn{3}{c}{ Mole fraction } \\
\hline $\mathrm{Ar}$ & 0 & 0.00250 \\
$\mathrm{CH}_{4}$ & 0.01159 & 0.02860 \\
$\mathrm{CO}$ & 0.12832 & 0.09183 \\
$\mathrm{CO}_{2}$ & 0.00157 & 0.00296 \\
$\mathrm{HCN}$ & 0.00004 & 0.00002 \\
$\mathrm{H}_{2}$ & 0.31452 & 0.35174 \\
$\mathrm{H}_{2} \mathrm{O}$ & 0.00621 & 0.01407 \\
$\mathrm{NH}_{3}$ & 0.00013 & 0.00024 \\
$\mathrm{~N}_{2}$ & 0.20640 & 0.20799 \\
$\mathrm{C}$ (graphite) & 0.33122 & 0.30005 \\
\hline${ }^{a}$ Properties obtained using CEA [17] code for chamber pressure of $1.35 \mathrm{MPa}$ \\
in equilibrium conditions.
\end{tabular}

the theoretical calculation. Therefore, the products flow from the gas generator, supplied to the secondary combustor as a fuel, was considered as a two-phase flow based on the assumption that thermochemical equilibrium condition is achieved in the gas generator chamber.

\subsection{Experimental Setup for a Connected-Pipe Test}

Connected-pipe tests have been conducted in numerous studies on ramjet and scramjet systems $[13,18,19]$ to demonstrate the combustor performance using accurate flow conditions and to investigate the combustion phenomena of air-augmented combustors. Figure 1 shows a schematic of the connected-pipe test facility for the lab-scale ducted rocket, which was designed at the Fine Rocket Propulsion Center of the Technion - Israel Institute of Technology. The connected-pipe experimental setup is mainly composed of hot air feed system that includes a vitiated air heater (VAH) [20] using hydrogen as a fuel, a gaseous fuel feed system, gas generator, ducted combustor with air inlet module, and data acquisition (DAQ) system.

In a connected-pipe setup, the air has to be fed at the appropriate stagnation temperature and pressure to simulate certain flight condition. The main air, regulated by a pressure regulator and sonic orifice, is supplied to the VAH from high pressurized air tanks, which have sufficient capability to supply a steady mass flow rate. Make-up oxygen is added to the air-feed line to compensate 


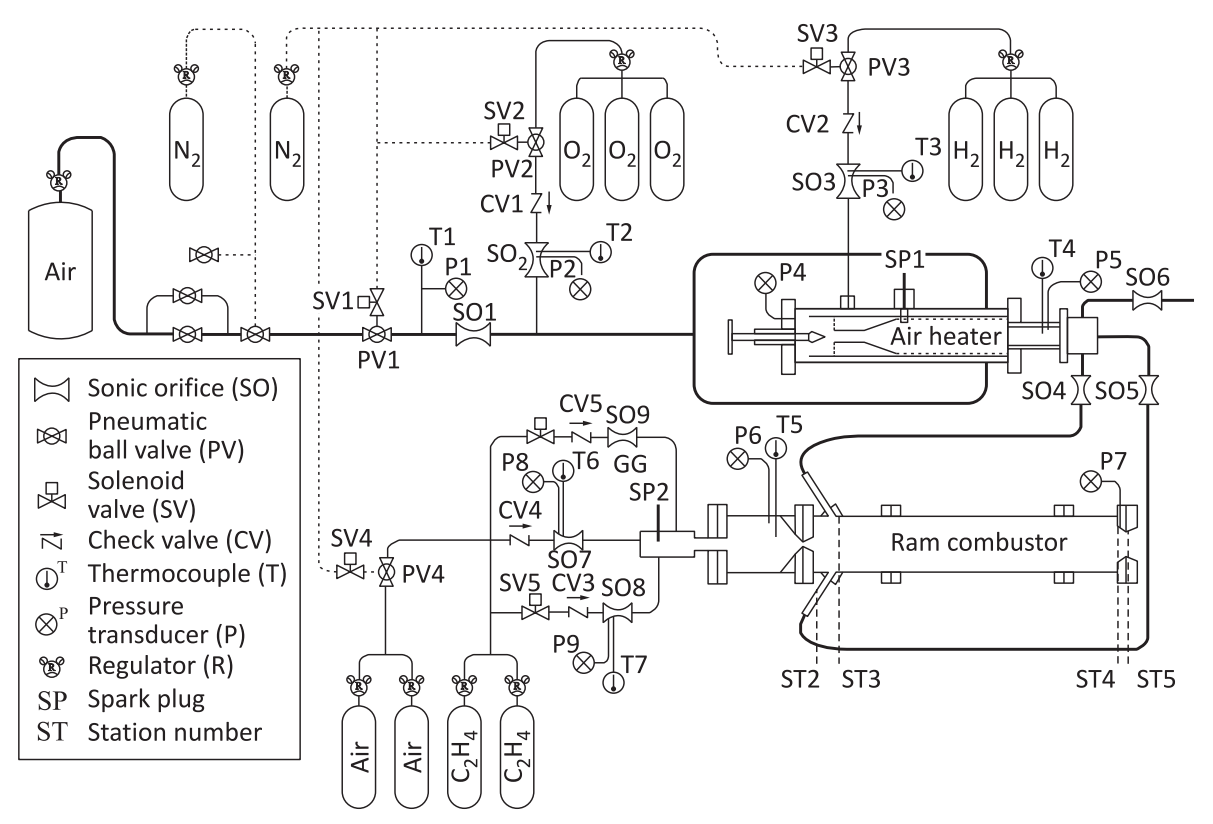

Figure 1 Schematic of the experimental setup

for oxygen, which is consumed by the combustion in the VAH. Then, oxygenenriched air is burned with hydrogen in the VAH to simulate the stagnation conditions downstream of the air inlets. The combustion products of the VAH exit the heater at pressure of $0.53 \mathrm{MPa}$ and temperature of $535 \mathrm{~K}$, which reflect the flight conditions at Mach number of 2.5 and altitude of $5 \mathrm{~km}$. A constant air intake ramp angle of $15^{\circ}$ was used for the three kinds of air inlet geometries. The hot air mass flow rate is determined by measuring the temperature and pressure in the feed line and also by measuring the contributions of the main air, hydrogen, and make-up oxygen.

The gaseous fuel feed system consists of ethylene and air feed lines in order to produce the fuel-rich exhaust from the ethylene/air with mixture ratio $\left(f_{g}\right)$ of 0.77 . The vaporized gaseous ethylene is supplied from the multiple cylinders without any pressurization, since liquid ethylene has high enough vapor pressure to supply the demanded mass flow rate. On the other hand, the mixture of ethylene and air is too rich to react at the required total mixture fraction. Therefore, the ethylene mass flow is divided to primary and secondary feed lines. The primary ethylene for stoichiometric mixture ratio is supplied into a pilot chamber and then the ethylene via the secondary line is added downstream the air and primary ethylene reaction region obtains the required mixture ratio of 0.77 . The air, stored under pressure in multiple cylinders, is also injected into the pilot 
chamber. The exhaust gas from the pilot chamber is injected into the gas generator chamber of internal volume of $980 \mathrm{~cm}^{3}$ and mixes with the secondary ethylene. Chamber pressure and exhaust temperature are measured in the gas generator to evaluate the fuel conditions.

The ducted combustor has a changeable air inlet module and several exhaust nozzles were used to maintain a similar chamber pressure under the various test conditions, such as significantly different total mass flow rates. All test procedures are automatically controlled by program logic controller using the DAQ board and LabVIEW software of National Instruments Corp. and data are collected in real time.

In the experimental investigation, the equivalence ratio $\varphi$ varied between 0.45 and 2.5. Table 2 shows these baseline specific conditions. The fuel mass flow rate was kept constant whereas the vitiated air mass flow rate was varied to simulate various flow conditions. Therefore, the air-to-fuel MR, which affects to the mixing characteristics, increased as the $\varphi$ was decreased. Momentum ratio was evaluated by the ratio between the mass flow rate multiplied by the velocity of the air and the fuel.

\subsection{Combustor Configurations and Test Conditions}

As mentioned previously, hot air is supplied to the secondary combustor through the multiple air inlets and then mixes and reacts with the fuel-rich gas from the gas generator. Thus, internal flow and combustion characteristics such as turbulent mixing between air and fuel-rich gas, formation of recirculation streams, and

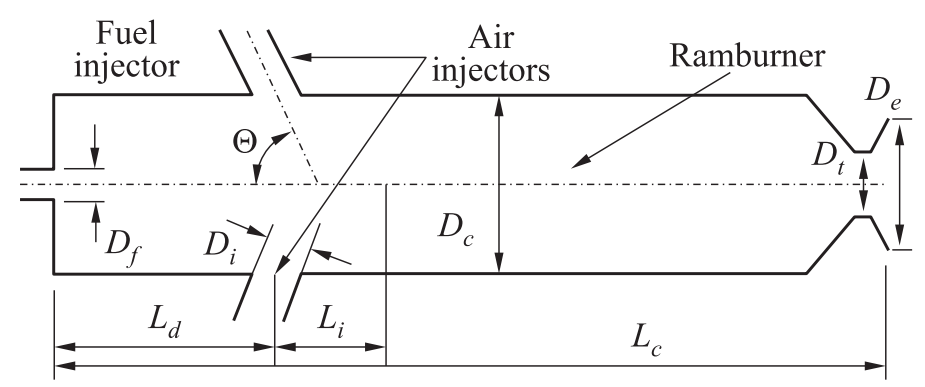

Figure 2 Schematic of the basic combustor 
Table 3 Geometries of the combustors

\begin{tabular}{rcc}
\hline$\theta$ & $D_{t}, \mathrm{~mm}$ & $D_{e}, \mathrm{~mm}$ \\
\hline $60^{\circ}$ & 23.5 & 27.0 \\
$90^{\circ}$ & 25.5 & 28.8 \\
$120^{\circ}$ & 28.0 & 31.3 \\
\hline
\end{tabular}

flame developing are strongly influenced by the air stream, which is determined by the configuration and integration of the air inlets.

In the present study, three kinds of combustors have been designed in order to evaluate the effect of the injection angle in a four-air inlet configuration: inlet angle $\theta$ of $60^{\circ}, 90^{\circ}$, and $120^{\circ}$. In addition, the effect of combustion pressure was investigated.

Figure 2 shows the basic combustor configuration. Combustion chamber diameter was $D_{c}=103 \mathrm{~mm}$, the total length $L_{c}=490 \mathrm{~mm}$, and the distance between the fuel injector and the air inlet was $L_{d}=70 \mathrm{~mm}$. Air inlet diameter was $D_{i}=16.5 \mathrm{~mm}$ and the fuel injection diameter was $D_{f}=4.8 \mathrm{~mm}$. The geometric specifications of the three combustors were summarized in Table 3.

The combustor configurations are shown in Fig. 3 for $\theta$ of $60^{\circ}, 90^{\circ}$, and $120^{\circ}$.

In addition, the effect of the combustion chamber pressure was investigated for the 120 degree geometry.
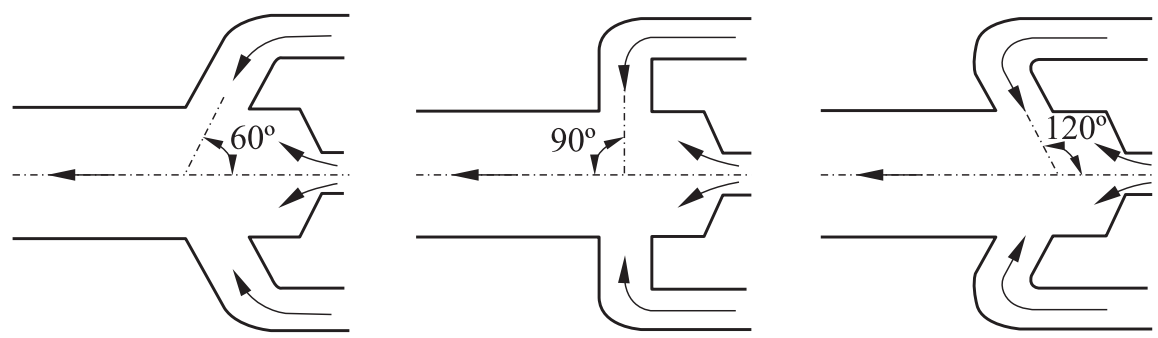

Figure 3 The combustor configurations

\section{RESULTS AND DISCUSSION}

Static firing tests were conducted using three different air inlet configurations and pressures between 2.5-6.5 bar. A total of 80 successful tests are summarized in Tables 4 and 5 for the three geometries and the pressures, respectively. In general, the experimental uncertainty was approximately $2 \%$ for the most measured properties. All tests were performed in accordance with the baseline experimental conditions presented in Table 2 .

The experimental characteristic velocity is calculated as follows:

$$
c_{\exp }^{*}=\frac{P_{c, \exp } A_{t} C_{D}}{\dot{m}_{a}+\dot{m}_{f}}
$$


Table 4 Experimental conditions and results for the inlet angle effect

\begin{tabular}{|c|c|c|c|c|c|c|c|c|c|}
\hline No. & $\theta^{\circ}$ & $\begin{array}{l}P_{C}, \\
\text { bar }\end{array}$ & $\varphi$ & $\begin{array}{l}\dot{m}_{\text {air }}, \\
\mathrm{kg} / \mathrm{s}\end{array}$ & $\begin{array}{c}\dot{m}_{f} \\
\mathrm{~kg} / \mathrm{s}\end{array}$ & $\begin{array}{c}T_{C} \\
\mathrm{~K}\end{array}$ & $\begin{array}{c}c^{*}, \\
\mathrm{~m} / \mathrm{s}\end{array}$ & $\begin{array}{c}\text { Thrust, } \\
\text { N }\end{array}$ & $\begin{array}{c}I_{\mathrm{sp}}, \\
\mathrm{s}\end{array}$ \\
\hline 1 & $60^{\circ}$ & 3.15 & 1.58 & 0.084 & 0.022 & 2228 & 1274 & 110 & 497 \\
\hline 2 & $60^{\circ}$ & 4.05 & 0.86 & 0.116 & 0.017 & 2481 & 1309 & 160 & 962 \\
\hline 3 & $60^{\circ}$ & 4.01 & 0.80 & 0.116 & 0.016 & 2500 & 1307 & 159 & 1027 \\
\hline 4 & $60^{\circ}$ & 4.02 & 0.78 & 0.116 & 0.015 & 2542 & 1306 & 159 & 1053 \\
\hline 5 & $60^{\circ}$ & 3.28 & 1.21 & 0.112 & 0.023 & 2248 & 1263 & 151 & 665 \\
\hline 6 & $60^{\circ}$ & 3.86 & 0.94 & 0.145 & 0.023 & 2031 & 1200 & 190 & 839 \\
\hline 7 & $60^{\circ}$ & 3.84 & 0.71 & 0.192 & 0.023 & 1726 & 1082 & 198 & 877 \\
\hline 8 & $60^{\circ}$ & 4.63 & 0.58 & 0.238 & 0.024 & 1738 & 1073 & 260 & 1126 \\
\hline 9 & $60^{\circ}$ & 5.07 & 0.49 & 0.287 & 0.024 & 1489 & 989 & 297 & 1275 \\
\hline 10 & $60^{\circ}$ & 4.03 & 0.74 & 0.190 & 0.024 & 1943 & 1146 & 209 & 901 \\
\hline 11 & $60^{\circ}$ & 4.03 & 0.96 & 0.145 & 0.024 & 2219 & 1249 & 199 & 855 \\
\hline 12 & $60^{\circ}$ & 2.54 & 2.10 & 0.067 & 0.024 & 1904 & 1208 & 81 & 347 \\
\hline 13 & $60^{\circ}$ & 2.27 & 2.42 & 0.057 & 0.024 & 1839 & 1204 & 75 & 321 \\
\hline 14 & $60^{\circ}$ & 4.90 & 0.95 & 0.146 & 0.023 & 2205 & 1244 & 208 & 907 \\
\hline 15 & $60^{\circ}$ & 3.91 & 1.17 & 0.115 & 0.023 & 2082 & 1216 & 158 & 703 \\
\hline 16 & $60^{\circ}$ & 3.08 & 1.65 & 0.085 & 0.024 & 2009 & 1214 & 109 & 465 \\
\hline 17 & $60^{\circ}$ & 3.36 & 0.97 & 0.115 & 0.019 & 2442 & 1311 & 139 & 751 \\
\hline 18 & $60^{\circ}$ & 3.39 & 1.14 & 0.116 & 0.022 & 2320 & 1284 & 146 & 664 \\
\hline 19 & $90^{\circ}$ & 3.15 & 1.59 & 0.084 & 0.023 & 2183 & 1262 & 95 & 425 \\
\hline 20 & $90^{\circ}$ & 5.31 & 0.45 & 0.287 & 0.022 & 1599 & 1023 & 308 & 1406 \\
\hline 21 & $90^{\circ}$ & 4.60 & 0.56 & 0.241 & 0.023 & 1681 & 1054 & 250 & 1114 \\
\hline 22 & $90^{\circ}$ & 4.06 & 0.69 & 0.196 & 0.023 & 1889 & 1126 & 202 & 900 \\
\hline 23 & $90^{\circ}$ & 4.03 & 0.91 & 0.146 & 0.023 & 2229 & 1246 & 186 & 842 \\
\hline 24 & $90^{\circ}$ & 3.35 & 1.16 & 0.115 & 0.023 & 2281 & 1277 & 144 & 652 \\
\hline 25 & $90^{\circ}$ & 3.33 & 1.15 & 0.115 & 0.023 & 2374 & 1261 & 146 & 659 \\
\hline 26 & $90^{\circ}$ & 2.31 & 2.26 & 0.059 & 0.023 & 1892 & 1213 & 58 & 259 \\
\hline 27 & $90^{\circ}$ & 3.27 & 1.51 & 0.087 & 0.023 & 2301 & 1290 & 113 & 517 \\
\hline 28 & $90^{\circ}$ & 4.27 & 1.08 & 0.119 & 0.022 & 2368 & 1297 & 165 & 769 \\
\hline 29 & $90^{\circ}$ & 4.83 & 0.82 & 0.151 & 0.021 & 2110 & 1203 & 198 & 955 \\
\hline 30 & $90^{\circ}$ & 4.89 & 0.84 & 0.148 & 0.021 & 2239 & 1241 & 194 & 939 \\
\hline 31 & $90^{\circ}$ & 4.05 & 1.34 & & 0.027 & 2003 & 1195 & 149 & 561 \\
\hline 32 & $90^{\circ}$ & 3.22 & 1.87 & 0.088 & 0.028 & 1887 & 1189 & 108 & 391 \\
\hline 33 & $90^{\circ}$ & 3.10 & 1.95 & 0.085 & 0.028 & 1825 & 1174 & 98 & 354 \\
\hline 34 & $90^{\circ}$ & 2.25 & 2.81 & 0.059 & 0.028 & 1526 & 1141 & 58 & 210 \\
\hline 35 & $120^{\circ}$ & 2.98 & 1.76 & 0.085 & 0.025 & 1827 & 1164 & 106 & 431 \\
\hline 36 & $120^{\circ}$ & 3.99 & 1.29 & 0.116 & 0.025 & 2056 & 1209 & 166 & 664 \\
\hline 37 & $120^{\circ}$ & 5.12 & 0.94 & 0.148 & 0.024 & 2347 & 1282 & 223 & 964 \\
\hline 38 & $120^{\circ}$ & 2.25 & 2.29 & 0.058 & 0.023 & 1823 & 1193 & 59 & 267 \\
\hline 39 & $120^{\circ}$ & 3.10 & 1.57 & 0.086 & 0.023 & 2051 & 1221 & 106 & 469 \\
\hline 40 & $120^{\circ}$ & 3.38 & 1.15 & 0.118 & 0.023 & 2211 & 1254 & 153 & 676 \\
\hline 41 & $120^{\circ}$ & 4.03 & 0.91 & 0.146 & 0.023 & 2222 & 1244 & 189 & 852 \\
\hline 42 & $120^{\circ}$ & 3.86 & 0.78 & 0.171 & 0.023 & 2150 & 1208 & 190 & 852 \\
\hline
\end{tabular}


Table 4 (continued) Experimental conditions and results for the inlet angle effect

\begin{tabular}{rcccccrrrr}
\hline \multirow{2}{*}{ No. } & \multirow{2}{*}{$\theta^{\circ}$} & $\begin{array}{c}P_{C}, \\
\mathrm{bar}\end{array}$ & $\varphi$ & $\begin{array}{c}\dot{m}_{\mathrm{air}}, \\
\mathrm{kg} / \mathrm{s}\end{array}$ & $\begin{array}{c}\dot{m}_{f}, \\
\mathrm{~kg} / \mathrm{s}\end{array}$ & $\begin{array}{c}T_{C}, \\
\mathrm{~K}\end{array}$ & $\begin{array}{r}c^{*}, \\
\mathrm{~m} / \mathrm{s}\end{array}$ & $\begin{array}{r}\text { Thrust, } \\
\mathrm{N}\end{array}$ & $\begin{array}{c}I_{\mathrm{sp}}, \\
\mathrm{s}\end{array}$ \\
\hline 43 & $120^{\circ}$ & 4.32 & 0.62 & 0.211 & 0.022 & 1890 & 1121 & 226 & 1030 \\
44 & $120^{\circ}$ & 5.22 & 0.45 & 0.291 & 0.022 & 1560 & 1011 & 296 & 1372 \\
45 & $120^{\circ}$ & 3.28 & 1.18 & 0.144 & 0.029 & 1380 & 990 & 139 & 494 \\
46 & $120^{\circ}$ & 3.02 & 1.00 & 0.170 & 0.029 & 1198 & 920 & 147 & 520 \\
47 & $120^{\circ}$ & 2.22 & 2.98 & 0.058 & 0.029 & 1452 & 1093 & 61 & 212 \\
48 & $120^{\circ}$ & 2.72 & 2.03 & 0.087 & 0.029 & 1354 & 1015 & 86 & 297 \\
49 & $120^{\circ}$ & 2.65 & 1.48 & 0.117 & 0.029 & 1234 & 943 & 101 & 349 \\
50 & $120^{\circ}$ & 2.55 & 1.53 & 0.115 & 0.030 & 1147 & 911 & 93 & 316 \\
51 & $120^{\circ}$ & 2.49 & 1.42 & 0.116 & 0.028 & 1131 & 900 & 88 & 323 \\
\hline
\end{tabular}

Table 5 Experimental conditions and results for the pressure effect

\begin{tabular}{ccccccccr}
\hline \multirow{2}{*}{ No. } & $\begin{array}{c}P_{C}, \\
\text { bar }\end{array}$ & $\varphi$ & $\begin{array}{c}\dot{m}_{\text {air }}, \\
\mathrm{kg} / \mathrm{s}\end{array}$ & $\begin{array}{c}\dot{m}_{f}, \\
\mathrm{~kg} / \mathrm{s}\end{array}$ & $\begin{array}{c}T_{C}, \\
\mathrm{~K}\end{array}$ & $\begin{array}{c}c^{*}, \\
\mathrm{~m} / \mathrm{s}\end{array}$ & $\begin{array}{c}\text { Thrust, } \\
\mathrm{N}\end{array}$ & $\begin{array}{r}I_{\mathrm{sp}}, \\
\mathrm{s}\end{array}$ \\
\hline 52 & 2.91 & 1.189 & 0.118 & 0.024 & 2419 & 1313 & 141 & 601 \\
53 & 3.17 & 0.930 & 0.152 & 0.024 & 1896 & 1152 & 108 & 457 \\
54 & 3.31 & 0.959 & 0.113 & 0.019 & 1851 & 1141 & 120 & 856 \\
55 & 3.33 & 0.502 & 0.219 & 0.019 & 1232 & 901 & 119 & 648 \\
56 & 3.34 & 1.151 & 0.115 & 0.022 & 2257 & 1265 & 146 & 660 \\
57 & 3.48 & 0.665 & 0.159 & 0.018 & 1523 & 1010 & 150 & 621 \\
58 & 4.03 & 0.909 & 0.146 & 0.023 & 2234 & 1247 & 187 & 842 \\
59 & 4.06 & 1.344 & 0.119 & 0.027 & 2019 & 1198 & 149 & 562 \\
60 & 4.06 & 0.690 & 0.196 & 0.023 & 1891 & 1126 & 202 & 900 \\
61 & 4.15 & 0.565 & 0.239 & 0.023 & 1561 & 1016 & 193 & 860 \\
62 & 4.34 & 1.277 & 0.114 & 0.025 & 2423 & 1312 & 172 & 706 \\
63 & 4.44 & 0.579 & 0.249 & 0.024 & 1647 & 1045 & 216 & 900 \\
64 & 4.50 & 0.679 & 0.225 & 0.026 & 1692 & 1065 & 261 & 1023 \\
65 & 4.60 & 0.559 & 0.241 & 0.023 & 1683 & 1055 & 251 & 1114 \\
66 & 4.73 & 0.600 & 0.253 & 0.026 & 1782 & 1088 & 249 & 986 \\
67 & 4.88 & 0.774 & 0.194 & 0.026 & 1905 & 1137 & 249 & 997 \\
68 & 4.89 & 0.837 & 0.148 & 0.021 & 2252 & 1241 & 194 & 939 \\
69 & 5.01 & 0.605 & 0.246 & 0.025 & 1804 & 1094 & 253 & 1020 \\
70 & 5.24 & 0.933 & 0.145 & 0.023 & 2068 & 1202 & 190 & 868 \\
71 & 5.31 & 0.450 & 0.292 & 0.022 & 1600 & 1024 & 307 & 1403 \\
72 & 5.34 & 0.692 & 0.223 & 0.026 & 1799 & 1098 & 276 & 1074 \\
73 & 5.56 & 1.085 & 0.138 & 0.025 & 2434 & 1314 & 221 & 887 \\
74 & 5.63 & 0.587 & 0.233 & 0.023 & 1901 & 1123 & 295 & 1294 \\
75 & 5.75 & 0.773 & 0.188 & 0.025 & 2219 & 1227 & 266 & 1097 \\
76 & 5.82 & 0.877 & 0.168 & 0.025 & 2333 & 1269 & 260 & 1060 \\
77 & 5.93 & 0.631 & 0.278 & 0.030 & 986 & 810 & 260 & 888 \\
78 & 5.98 & 0.576 & 0.240 & 0.024 & 1606 & 1031 & 276 & 1199 \\
79 & 6.29 & 0.590 & 0.238 & 0.024 & 1539 & 1010 & 280 & 1193 \\
80 & 6.50 & 0.547 & 0.264 & 0.025 & 1589 & 1024 & 304 & 1264 \\
\hline & & & & & & & &
\end{tabular}


where the discharge coefficient $C_{D}$ was assumed to be 1.0 for all test cases. The measured static pressure, $P_{c}$, is used as the stagnation pressure at the combustor. Considering that ratio between the nozzle entrance area to the throat area has a relatively large value of 13.5 , this estimation is reasonable.

The equation to determine the experimental temperature at the end of the combustor is given as follows:

$$
T_{c, \exp }=T_{c, \mathrm{th}}\left(\frac{c_{\mathrm{exp}}^{*}}{c_{\mathrm{th}}^{*}}\right)^{2} .
$$

The theoretical characteristic velocity, $c_{\mathrm{th}}^{*}$, and theoretical stagnation temperature, $T_{c, t h}$, are calculated using CEA [17] at the operating conditions, i.e.,

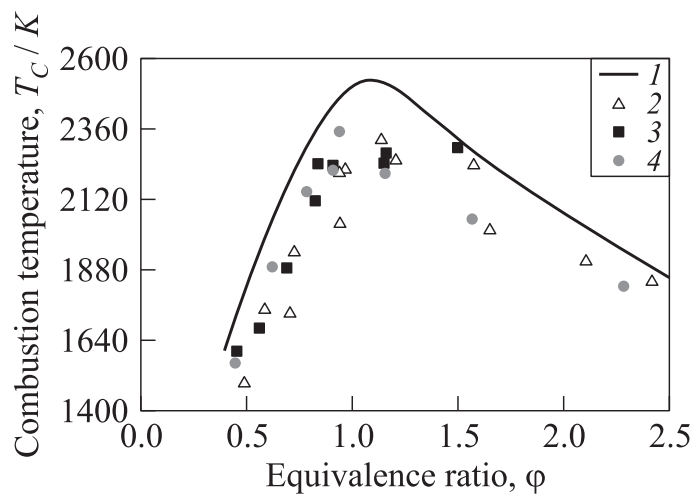

(a)

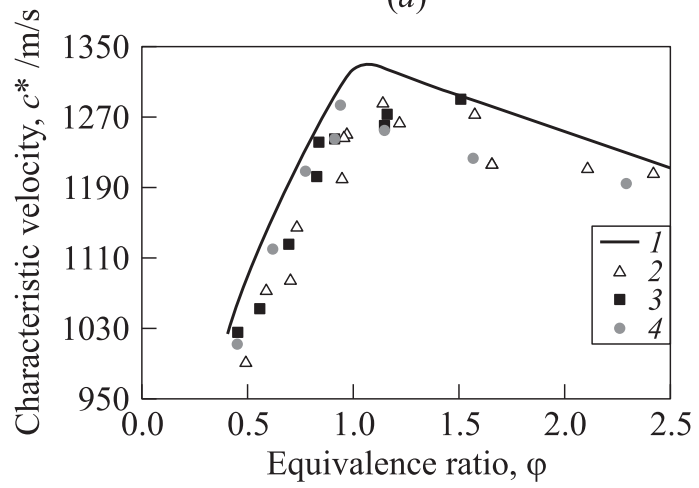

(b)

Figure 4 The experimental combustion temperature $(a)$ and characteristic velocity $(b)$ vs. equivalence ratio: 1 - theoretical model (CEA); $2-60$ degree air-inlet; 3 - 90 degree air-inlet; and $4-120$ degree air-inlet 
temperature, pressure, mass flow rate, exhaust compositions, and mass fraction of the vitiated air and exhaust from the gas generator.

The experimental combustion temperatures and characteristic velocities for the three configurations vs. the equivalence ratio are shown in Fig. 4. The solid line represents the theoretical values.

Figure 4 indicates that the 120 degree air-inlet configuration produces higher values for equivalence ratios below stoichiometric. This can also be seen in Fig. $5 a$ that shows $c^{*}$ efficiency. In general, efficiencies about 0.95 were obtained.

The reason for this result is the better mixing because of the injection against the main flow, which results in higher residence times. For fuel-to-air ratios higher than stoichiometric, a relatively large content of soot particles cannot complete their burning in all cases.

The experimental specific impulse [Thrust/ $\left.\left(g m_{f}\right)\right]$ for the three configurations vs. the equivalence ratio is presented in Fig. $5 b$.

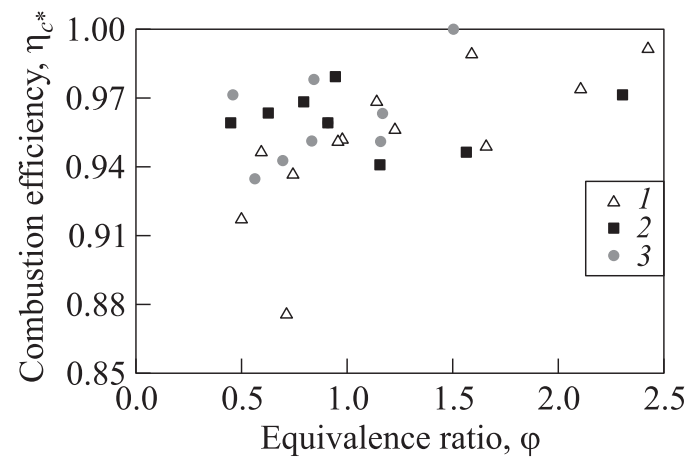

(a)

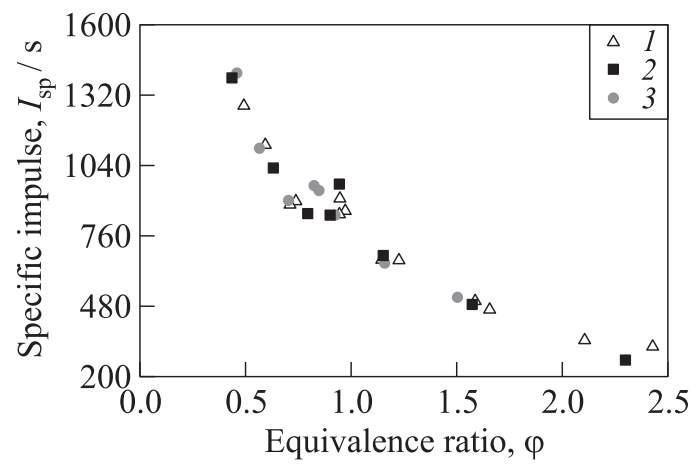

(b)

Figure 5 The $c^{*}$ efficiency $(a)$ and specific impulse $(b)$ vs. equivalence ratio: 1 60 degree air-inlet; $2-90$ degree air-inlet; and 3-120 degree air-inlet 


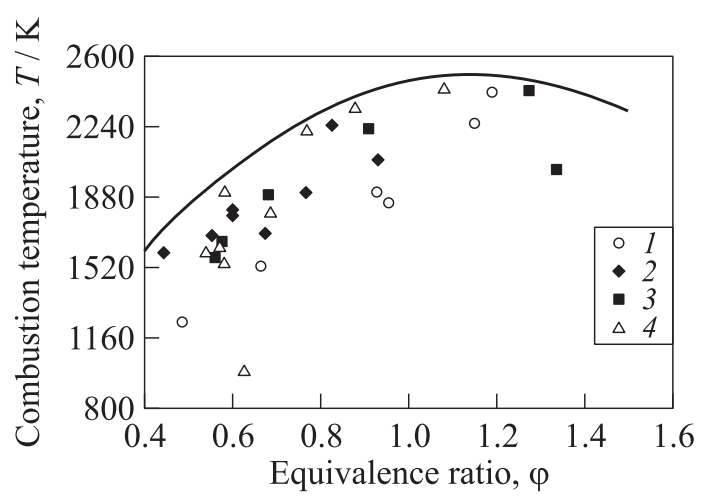

Figure 6 The experimental combustion temperature vs. equivalence ratio for various pressures: $1-2.5<p_{\mathrm{CC}}<3.5 ; 2-3.5<p_{\mathrm{CC}}<4.5 ; 3-4.5<p_{\mathrm{CC}}<5.5$; and $4-$ $5.5<p_{\mathrm{CC}}<6.5$

As expected, $I_{\mathrm{sp}}$ decreases st increasing of the equivalence ratio.

The effect of pressure is more complex. In general, increase of the pressure results in decrease of the gas velocity; consequently, the residence time of the gases in the combustor increases. The combustion temperature dependence on the equivalence ratio and the pressure is presented in Figs. 6 and $7 a$, respectively. From these figures, it is evident that the energetic performance increases with increasing pressure.

Thrust, as expected, was found to increase with pressure as shown in Fig. $7 b$. Higher values were received for the low equivalence ratios because of the higher inlet air mass flow rate. The specific impulse decreases with increasing the equivalence ratio and increases with increasing pressure as shown in Fig. 8.

\section{CONCLUDING REMARKS}

Connected-pipe experiments were conducted in a ducted rocket combustor at various equivalence ratios to evaluate the combustion performance of a ducted rocket combustor with an emphasis on the air inlet angle and pressure effects. The experimental results showed a good agreement with the designed experimental conditions and the $c^{*}$ efficiency resided in the range $87 \%-95 \%(\varphi<1)$. As regards the air inlet configurations, all three air inlet angles provided sufficient flame stability by recirculating the gaseous stream. The characteristic velocities and the temperatures of all three inlet angles were close to each other, whereas those of $120^{\circ}$ were higher in comparison with the other configurations for equivalence ratios lower than 1 . As in theory, the characteristic velocity and 


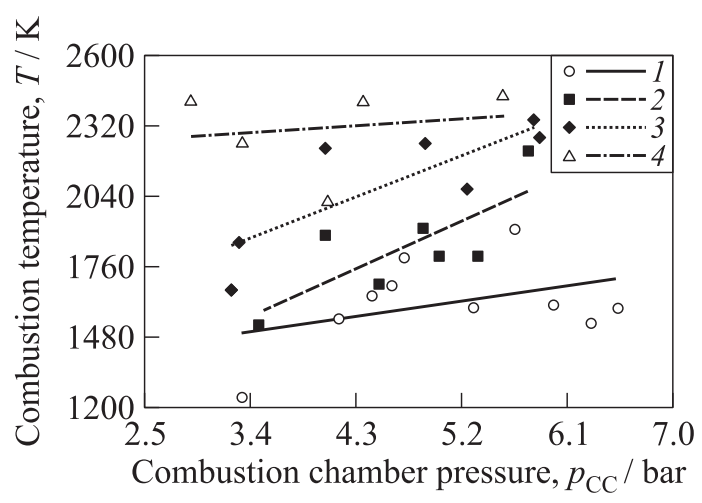

(a)

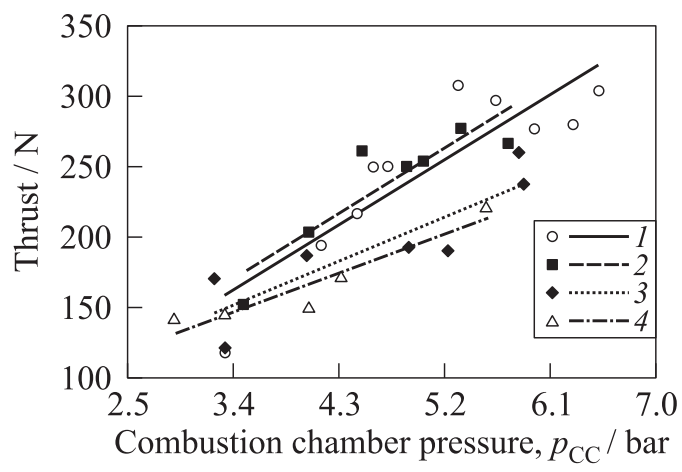

(b)

Figure 7 The experimental combustion temperature $(a)$ and thrust $(b)$ vs. pressure for various equivalence ratios: $1-0.45<\varphi<0.60 ; 2-0.60<\varphi<0.80 ; 3-$ $0.80<\varphi<1.00$; and $4-1.00<\varphi<1.50$. Signs refer to experiments and curves to theory

the temperature were found to increase with increasing the equivalence ratio until it becomes about 1 and then decrease with further increase in $\varphi$.

Pressure affects significantly the energetic performance and characteristic velocity and specific impulse were found to increase with increasing pressure.

\section{ACKNOWLEDGMENTS}

The authors thank Mr. Alexander Kuznetsov and Mr. Doron Har-Lev for their kind assistance. 


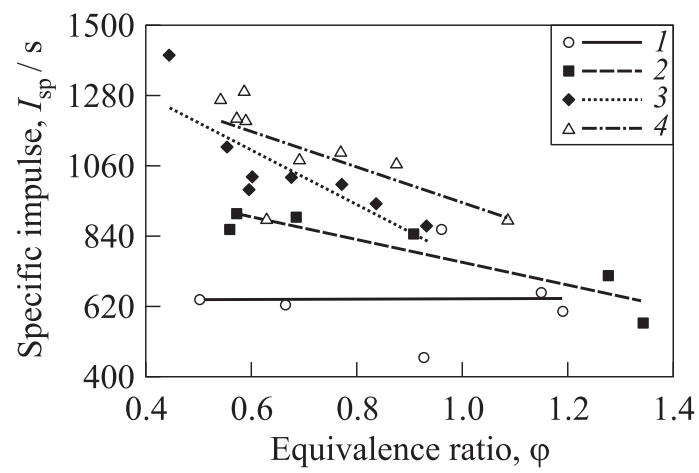

Figure 8 Specific impulse vs. equivalence ratio: $1-2.5<p_{\mathrm{CC}}<3.5 ; 2-3.5$ $<p_{\mathrm{CC}}<4.5 ; 3-4.5<p_{\mathrm{CC}}<5.5$; and $4-5.5<p_{\mathrm{CC}}<6.5$. Signs refer to experiments and curves to theory

\section{REFERENCES}

1. Fry, R. S. 2004. A century of ramjet propulsion technology evolution. J. Propul. Power 20:27-58.

2. Frederick, R. A., Jr., and I. Komai. 1996. Propellant design relationships for throttled gas generators. J. Propul. Power 12:614-616.

3. Besser, H., H. Weinreich, and G. Kurth. 2008. Fit for mission-design tailoring aspects of throttleable ducted rocket propulsion systems. AIAA Paper No. 20085262 .

4. Hweitt, P. W. 2008. Status of ramjet programs in the United States. AIAA Paper No. 2008-5265.

5. Nakayama, H., Y. Ikegami, A. Yoshida, K. Koon, K. Watanabe, H. Tokunaga, H. Shimizu, and S. Kanaizumi. 2009. Full-scale firing tests of variable flow ducted rocket engines employing GAP solid fuel gas generator. AIAA Paper No. 2009-5121.

6. Pinto, P. C., and G. Kurth. 2011. Robust propulsion control in all flight stages of a throttleable ducted rocket. AIAA Paper No. 2011-5611.

7. Liou, T. M., L. Chen, and S. M. Wu. 1993. Effects of momentum ratio on turbulent non-reacting and reacting flows in a ducted rocket combustor. Int. J. Heat Mass Tran. 36:2589-2599.

8. Brophy, C. M., C.W. Hawk, and J. M. Bush. 2001. An investigation of four-inlet ducted rocket engine flameholding characteristics. AIAA Paper No. 1997-2846.

9. Kurth, G., and C. Bauer. 2008. Air intake development for supersonic missiles. AIAA Paper No. 2008-5263.

10. Clark, W.H. 1982. Experimental investigation of pressure oscillations in a side dump ramjet combustor. J. Spacecraft Rockets 19:47-53.

11. Chuang, C. L., D. L. Cherng, W. H. Hsieh, G. S. Settles, and K. K. Kuo. 1989. Study of flowfield structure in a simulated solid-propellant ducted rocket motor. AIAA Paper No. 89-0011. 
12. Dijkstra, F., A. E. H. J. Mayer, K. J. Wilson, R. A. Smith, and K. C. Schadow. 1995. Ducted rocket combustion experiments at low gas generator combustion temperatures. AIAA Paper No. 95-2415.

13. Mayer, A. E. H. J., and R. A. Stowe. 2000. Experimental study into mixing in a solid fuel ducted rocket combustion chamber. AIAA Paper No. 2000-3346.

14. Kim, S., and B. Natan. 2015. Inlet geometry and equivalence ratio effects on combustion in a ducted rocket. J. Propul. Power 31:619-631.

15. Kubota, N., and T. Kuwahara. 1991. Combustion of energetic fuel for ducted rockets (I). Propell. Explos. Pyrot. 16:51-54.

16. Kubota, N., and T. Sonobe. 1988. Combustion mechanism of azide polymer. Propell. Explos. Pyrot. 13:172-177.

17. Gordon, S., and B. J. McBride. 1994. Computer program for calculation of complex chemical equilibrium compositions and applications. NASA RP-1311.

18. Dunsworth, L.C., and G. J. Reed. 1979. Ramjet engine testing and simulation techniques. J. Spacecraft Rockets 16:382-388.

19. Propulsion and Energetics Panel Working Group 22. 1994. Experimental and analytical methods for the determination of connected-pipe ramjet and ducted rocket internal performance. AGARD Advisory Report AGARD-AR-323.

20. Cohen-Zur, A., and B. Natan. 1998. Experimental investigation of a supersonic combustion solid fuel ramjet. J. Propul. Power 14:880-889. 